\title{
ADAPTACIONES DE CUENTOS DE HADAS EN LA LITERATURA INFANTIL Y JUVENIL IBEROAMERICANA: TRES TEXTOS RELEVANTES CERRANDO UN SIGLO
}

\author{
Lillyam Rosalba GONZÁLEZ ESPINOSA \\ Universidad de Ostrava
}

\begin{abstract}
En): This article aims to present and compare three adaptations of Little Red Riding Hood published in Latin America around the end of the 20th century: Caperucita en Manhattan (1990) by Carmen Martín Gaute, Caperucita Roja tal y como se la contaron a Jorge (1996) [Little Red Riding Hood (as told to George)] by Luis Pescetti, and Caperucita Roja y otras historias perversas (2003) [ Little Red Riding Hood and other wicked stories] by Triunfo Arciniegas. The article addresses the main structure of these fairy tales, in comparison with the versions of Perrault and Brothers Grimm and how the retelling adds elements that bring new meanings to the text.
\end{abstract}

Keywords (En): children's literature; Little Red Riding Hood; retelling; Ibero-America

\begin{abstract}
Resumen (Es): Este artículo tiene como objetivo presentar y comparar tres adaptaciones de Caperucita Roja publicadas en América Latina a fines del siglo XX. El artículo aborda la estructura principal de estos cuentos de hadas, comparándolas con versiones de Perrault y los hermanos Grimm. Si bien el siglo XXI ha traído nuevas versiones y nuevas aproximaciones a este relato de la literatura infantil, este artículo se centra principalmente en tres propuestas que tuvieron gran acogida al momento de su publicación y que están dirigidas al público infantil y juvenil.
\end{abstract}

Palabras clave (Es): literatura infantil; Caperucita Roja; adaptaciones; Iberoamérica

\section{Introducción}

Caperucita Roja no necesita presentación: de los cuentos de hadas universalmente conocidos es este uno de los que más fácilmente reconocemos. Cuando revisamos las diferentes versiones podemos encontrar ligeras variantes, pero básicamente su estructura y personajes se mantienen: el lobo, Caperucita, la mamá de Caperucita, la abuelita y, según la adaptación, el leñador/cazador/labrador. La niña que, ataviada con una caperuza roja, iba a llevarle algo de comer a su abuelita enferma y en el camino se encontró con el lobo, es un relato reversionado decenas de veces. En español hay al menos un centenar y en otras lenguas hay equivalentes similares. Por esta misma razón es uno de los cuentos de hadas más estudiados por la crítica. Sirva apuntar que la permanencia de su estructura y personajes, así como la posibilidad de hacer seguimiento al cuento desde la publicación de Perrault en 1697, e incluso antes si nos referimos a la versión del siglo XI, facilita su estudio; Caperucita Roja contiene elementos innegables para variados análisis; de hecho, la tensión sexual, la relación hombre-mujer dentro de parámetros tradicionales, enfocados desde una mirada masculina, el discurso literario sobre los roles sexuales y la conducta - en palabras de Zipes (1983) - son algunos de los temas de análisis que ha abarcado el cuento.

A la par con la crítica hay un interés en los escritores por reelaborar, construir y reinterpretar los cuentos de hadas, manteniendo el hipotexto tanto de Perrault (1697), como de Grimm (1812) para crear relaciones hipertextuales. Es importante 
apuntar también el especial interés en mostrar a los personajes femeninos desde un punto de vista que supere el tradicional maniqueo de bella-bestia, víctima-verdugo y transformar o matizar los cuentos con nuevos elementos que elaboren personajes en los que las niñas no son únicamente princesas o en las que la trama toma otros giros para diversificar o modernizar aspectos que se consideran anticuados, o como afirma Noguerol, con escritoras que se animan en aproximaciones "que no se quedan en el maniqueísmo de ciertos postulados feministas" (NOGUEROL, 2001:1).

Se quiere hacer la salvedad de que este artículo no se enfocará en dichas temáticas, aunque reconoce la relevancia de tales estudios, sino que hará un acercamiento a los componentes narrativos que se conservan, prescinden o reelaboran a partir de las dos versiones hipotextuales del cuento infantil. Nos enfocaremos en tres textos puntuales, destinados al público infantil, publicados en Iberoamérica y que han sido relevantes para la crítica literaria.

\section{Del cuento y su estructura}

En una rápida mirada panorámica a Caperucita Roja, el estudio de Susana González «¿Existía Caperucita Roja antes de Perrault?» (2003) resalta las versiones orales que existen del cuento incluso en lugares en donde seguramente la versión de Perrault no llegó a ser conocida tempranamente, como es el caso de las culturas orientales en donde también hay relatos de tradición oral con semejanzas a Caperucita; pero el hecho más claro a nivel de escritura tiene que ver con un texto del siglo XI escrito por Egberto de Nájera, en el que el autor expone que los versos que está escribiendo son de "procedencia popular» (GONZÁLEZ, 2003: 17) y que muestran el germen del relato que después sería recogido por Charles Perrault siglos más tarde. El verso en cuestión está en el libro Fecunda Ratis, que recoge proverbios, cuentos y fábulas. Los versos rezan:

[...] Al sacar a una iglesia a una niña de pila/ le regalaron una caperucita roja./ La santa quincuagésima se celebró su bautizo cuando la niña cumplía cinco años./ Después mientras andaba sin cuidado ninguno,/ le salió al paso un lobo que se la llevó al bosque/ y dejó por comida la presa a sus cachorros,/ que la acosaron juntos y, no pudiendo herirla,/ mansamente empezaron a lamer su cabeza./ «No me rompáis ratones -dijo entonces la niña-,/ esta caperucita que me dio mi padrino.» Templa el Dios que los hizo, los destemplados ánimos. (GonZÁLEZ, 2003: 17)

Se observa que elementos clave del cuento de Perrault como son la niña, la caperuza (en el texto citado por González aparece traducido como caperucita roja, pero literalmente el término adecuado sería -como indica la autora- «túnica roja»; puede inferirse que esta túnica le cubría la cabeza a la niña ya que ella exclama que no le lamieran la cabeza porque podían arruinarle la prenda que llevaba puesta), el bosque y el lobo son nombrados en esta versión medieval, también la culpabilidad de la niña por lo sucedido al andar «sin cuidado alguno» y ser abordada por un lobo. Aunque el relato difiera del que posteriormente sería conocido, hay elementos que coinciden: personajes centrales, una prenda de ropa, la niña sola jugando descuidadamente y la niña abordada por el lobo. Los versos citados son pues la primera referencia escrita conocida sobre el cuento que ahora conocemos bajo el nombre de Caperucita Roja. Ahora bien, si se continúa rastreando habría antecedentes incluso anteriores, en la Grecia Antigua, apunta González, en donde 
hay relatos en los que una niña es expuesta al peligro o al mal representado frecuentemente en un ser de características licántropas. No se trata de un motivo creado en Francia o por Charles Perrault, es un cuento de tradición oral del que, en el mundo de la literatura, se ha fijado como texto primario -hipotexto- la versión del francés.

La versión de Perrault se centra en la niña y el lobo. La madre aparece en las primeras líneas y la abuela unas más allá antes de que el lobo se la coma. La escena central de esta versión ocurre en la habitación en la que la niña, luego de obedecer a la supuesta abuela - que la invita a quitarse la ropa y meterse a la cama con ellaenuncia una serie de exclamaciones que resaltan las características atípicas de la abuela: brazos grandes, orejas grandes, nariz grande, hasta llegar al «iQué dientes tan enormes, abuelita!», momento en que ocurre la acción final que cierra el cuento: el lobo se come a la niña. A continuación, viene la moraleja del cuento en donde queda clara la intención de Perrault de alertar a las mujeres jóvenes de no confiar en los extraños, máxime cuando son aduladores:

Se ve por este cuento que las niñas, sobre todo las que tienen bonita cara y gentil el talle, hacen mal en dar oídos a todo el mundo, pues su imprudencia puede costarles cara. Un lobo se comió á Caperucita. Bueno será que se tenga en cuenta que no todos los lobos son iguales. Los hay que corteses y agradables siguen y enamoran á las jóvenes en las casas y los paseos. Estos lobos son ¡ay! los de más peligro. (PERRAUlt, 1892:20)

Como se observa, la versión de Perrault no es originalmente un cuento para niños, y las líneas en las que se subrayan estos aspectos desaparecen en las versiones que sí lo son, mientras que otros elementos que apenas se nombran toman relevancia. Por ejemplo, la intervención de la madre que le insiste a Caperucita que no salga del camino o la presencia de hombres trabajadores, que pueden ser labradores, leñadores o cazadores -depende de la traducción o versión-que alertan al lobo de no actuar: «se encontró á maese Lobo. El muy tunante se hubiera comido de buena gana á la niña; pero no se atrevió porque unos labradores que se hallaban cerca, podían verle» (PERRAULT, 1892: 17); en otras versiones, estos son los que salvan a Caperucita y castigan al lobo. La presencia de la madre y de los labradores/leñadores/cazadores en otras versiones subrayan dos puntos que suelen estudiarse en Caperucita como un cuento infantil: uno tiene que ver con la desobediencia de la hija hacia su madre y otro, con el hombre que salva y da un escarmiento al lobo y subraya la ingenuidad de Caperucita, la valentía del salvador y su superioridad moral y física frente a la heroína y la victoria del bien sobre el mal. Pero el aspecto fundamental que desaparece de las versiones para niños es la escena de la cama. Ni el lobo le menciona a la niña que se desnude ni que se meta a la cama con ella, estas líneas problemáticas se obvian en las otras versiones. La versión de Perrault es, por consiguiente, no tan conocida o recurrida cuando se trata de presentarla a los niños. Es decir, el aspecto sexual innegable que tiene la versión del cuento de Perrault y su destinatario, que son las jóvenes casaderas, dejan de ser principales en la mayoría de las adaptaciones. Se regresa a este motivo cuando la versión tiene una intención amorosa o sexual, tratándose, en la mayoría de los casos, en variantes dirigidas a público adulto. 
En contraste, la versión de los hermanos Grimm (1812) es el hipotexto más recurrido en las reelaboraciones de Caperucita Roja para el público infantil. El ir directo a casa de la abuela sin salirse del bosque que le recomienda la madre a Caperucita se convierte en motivo principal (la moraleja del cuento se enlaza con este motivo), la presencia del salvador en las botas de un cazador que rescata a Caperucita y escarmienta al lobo, como ya mencionamos, sirve como colofón al cuento. El paseo por el bosque es una escena más extensa en la que la niña juega y recoge flores para la abuela, subrayando la desobediencia a la madre y la complacencia ante las sugerencias del lobo, ya que es él quien le ha propuesto ir por otro camino a casa de la abuela. La escena del diálogo entre el lobo disfrazado de abuela y Caperucita permanece. La moraleja de Grimm «Y Caperucita Roja retornó segura a su casa y en adelante siempre se cuidó de no caer en las trampas de los que buscan hacer daño» (GRIMM, 2013:186) resalta un motivo diferente al de Perrault, el lobo no se sale con la suya y la niña regresa segura a su casa, con la lección aprendida, se aleja de la moraleja de tipo sexual.

Cabe decir que esta moraleja es una reafirmación de una ya proclamada por Caperucita líneas atrás: «Mientras viva, nunca me retiraré del sendero para internarme en el bosque, cosa que mi madre me había ya prohibido hacer» (GRIMM, 2013:186). Esta duplicación de la moraleja ocurre porque la versión de Grimm incluye un breve episodio posterior, con lobo y abuela incluidos, en el cual la niña actúa «a la defensiva» porque ya tiene la experiencia de su primer encuentro con un lobo. Si bien este final no se cita con frecuencia, sí deja en evidencia el interés de exaltar la moraleja dirigida a los niños y al comportamiento que deben tener en sociedad, tomando como referencia primera las indicaciones de sus padres.

\section{Versiones y reversiones}

En la literatura infantil suele tomarse el hilo argumentativo del cuento a partir del hipotexto de los hermanos Grimm y, en consecuencia, suele definirse a Caperucita como una narración sobre una niña desobediente. La ambigüedad del cuento, así como su estructura esquemática (la heroína que sale de casa, el mal que acecha, la lección impartida, el ayudante, salvador, etc,) hacen frecuente su reelaboración en la literatura. Las zonas grises del cuento facilitan su reescritura, es decir, su estructura base, sus personajes y escenas prototípicas se mantienen de versión en versión, pero cada una de estas escenas puede ser enriquecida con nuevos elementos, de acuerdo con la época o el narrador. Cualquier lector que se acerque a una adaptación del cuento reconocería que se trata de Caperucita Roja y lo situaría como un cuento de su niñez, de hadas, sucedido hace mucho tiempo, en algún lugar lejano (el érase una vez que ubica atemporalmente estos relatos) y podría definir fácilmente su línea argumental y personajes; además, reconocería los nuevos elementos que ha traído a colación cada nueva versión. Al ser un relato fácilmente reconocible y que acompaña al lector desde su primera infancia, las nuevas versiones apelan a ese primer lector y también a un lector más adulto que entiende de qué se trata el asunto al enseñarle una nueva forma de leer el popular cuento. Es ese punto en el que queremos detenernos ya que, a través de nuevas Caperucitas, los distintos relatos se salen del plano estrictamente infantil y apostrofan al lector adulto 
que está leyendo estos libros con los niños y los jóvenes debido a que parte de estos guiños no van dirigidos a un lector infantil que está escuchando el cuento por primera vez sino a uno que ya conoce el hipotexto y que también se ve interpelado por este.

En las tres versiones de los cuentos que se presentan a continuación no hay ninguna necesidad de hacer un pie de página para explicar cuál es la fuente de estos textos, el narrador da por hecho que el lector ya lo conoce y, por tanto, desde un principio se enfoca en ese juego intertextual. Dicha dinámica varía en complejidad teniendo en cuenta para quiénes van dirigidos estos títulos, asunto que no es ajeno a la literatura infantil pues normalmente se clasifican los libros de acuerdo con las edades y así también surgen unos ejes temáticos que se recomiendan trabajar. Según las edades de los lectores ideales de estas tres versiones, tanto la de Grimm como la de Perrault toman diferentes matices, alejándose, como se verá a continuación, de la versión tradicionalmente infantil en la medida que el posible lector va haciéndose un lector adulto. A continuación, se representarán rápidamente tres títulos de modo descendente: del dirigido a público adolescente, Caperucita Roja y otras historias perversas; pasando por el lector en marcha de 12 o 13 años en Caperucita en Manhattan (1990), hasta los primeros lectores con Caperucita Roja tal y como se la contaron a Jorge (1996).

\subsection{Una caperucita perversa: la versión de Triunfo Arciniegas}

Caperucita Roja y otras historias perversas, del colombiano Triunfo Arciniegas (2003), está clasificado en franja juvenil. En esta versión un lobo es víctima de Caperucita.

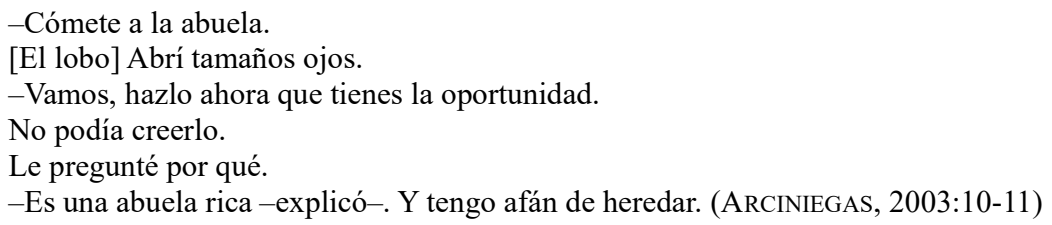

El lobo acepta matar a la abuela de la niña porque Caperucita quiere quedarse con el dinero de la abuela y el narrador juega con el ya instaurado papel de lobo como el agresor (siguiendo la clasificación de Propp). El cuento no ocupa más de cuatro páginas y hay algunos intertextos de las versiones de Grimm y Perrault sin reconstruir del todo el relato. También cambia el narrador a primera persona a través del lobo que está haciendo una confesión de por qué se comió a la abuela. En resumen, es una vuelta de tuerca a la versión tradicional, el lobo resulta siendo víctima de una mujer sin escrúpulos que le tiende una trampa para lograr su cometido, tal y como lo hace el lobo en Perrault. En esta versión, Caperucita es la agresora, se aprovecha de los sentimientos nobles del lobo que resulta ser condenado por haberse comido a la abuela; la niña, en cambio, goza de la herencia que le correspondió al morir la abuela. Es pertinente apuntar que el lobo se dirige a una audiencia con miras a ser redimido y se ironiza o se reelaboran las escenas prototípicas con el fin de causar un efecto en el lector, hay por tanto una suposición por parte del autor de que el lector conoce ya otras versiones del cuento. La escena citada antes es una parodia del momento del diálogo central entre el lobo y 
Caperucita; dichas parodias se repiten en otros momentos de la narración y así se establece cómo la niña subvierte sus intervenciones confrontando al lobo y su rol tradicionalmente reconocido: la niña no es ni ingenua, ni inocente, no lleva ninguna caperuza roja, sale al bosque con sus amigos y tampoco va hacia casa de la abuela a cumplir con un mandato de la madre.

-¿Y qué llevas en el canasto?

-Un rico pastel para mi abuelita. ¿Quieres probar?

Casi me desmayo de la emoción. Caperucita me ofrecía su pastel. ¿Qué debía hacer? [...] me parecía tan amable, tan bella. Dije que sí. [...]

-Es un experimento -dijo Caperucita-. Lo llevaba para probarlo con mi abuelita pero tu apareciste primero. Avísame si te mueres. (ARCINIEGAS, 2003: 8-9)

De nuevo, encontramos elementos de confrontación con los cuentos de hadas en esta versión de Arciniegas. El lobo no puede hacer gran cosa pues, como él mismo afirma «solo soy el lobo de la historia» (11). Esta caracterización del lobo se encuentra con frecuencia en las reversiones de Caperucita, a veces reivindicando su figura a través de un animal humanizado o en una inversión de roles, «mediante el humor y la polifonía textual» (MANGIONE, 2018: 115).

La presencia de los otros personajes figura a través de referencias que hace el lobo: no hay leñadores sino policías que están de lado de la versión de Caperucita; están la madre y el padre - este es ausente en los dos hipotextos principales-, y la abuela, que aparece cuando el lobo la nombra en su testimonio. El lobo lleva las ropas de la abuela por pedido explícito de Caperucita, como parte de su coartada para culpabilizarlo del crimen de la abuela. «Por eso me vieron vestido de abuela. No quería comerme a Caperucita, como ella gritaba. Tampoco me gusta vestirme de mujer, mis debilidades no llegan hasta allá. Siempre estoy vestido de lobo» (11).

Como se trata de un texto dirigido a un público juvenil-adulto, el cuento no sigue la estructura típica de los cuentos de hadas. Como ya se apuntó el relato está contado en primera persona, a modo de testimonio por el lobo que se dirige a una audiencia, el autor se vale de las escenas centrales o prototípicas de Caperucita Roja para parodiarlas e incluirlas dentro de su relato que consigue apuntar hacia unos personajes que encarnan otros roles, subvirtiendo los tradicionales. Arciniegas aprovecha el trasfondo sexual de Perrault y le apuesta a una historia de amor no correspondido. Una versión del lobo enamorado, utilizado por una niña malvada que se aprovecha de éste. Se aleja de la moraleja relacionada con la desobediencia o sobre las consecuencias de desviarse del camino correcto y se acerca a la moraleja de Perrault, pero ahora aplicada al lobo como víctima de una niña mañosa.

\subsection{Una Caperucita en la ciudad: la versión de Martín Gaite}

En Caperucita en Manhattan (1990), de la española Carmen Martín Gaite, hay una serie de intertextos no solo de Caperucita sino de otros clásicos de la literatura infantil, en especial de Alicia en el país de las maravillas, la niña protagonista es un híbrido entre estos dos personajes y como nos lo dice el mismo título el reino de las hadas está en Nueva York. El lector infiere desde antes de empezar la novela que se trata de una versión moderna del cuento de hadas. En este libro, Caperucita es una niña en proceso de formación, una consumida lectora, que se debate entre la vida 
que tiene, los valores que se le imponen y lo que quisiera vivir, en otras palabras, temáticas sugerentes y constantes en la literatura para jóvenes. Bajo esta premisa, Caperucita se identifica con la niña del cuento de hadas en que no se le parece, en que sus valores no coinciden con los que los cuentos tradicionales le presentan y, por esa misma razón, critica e impone su opinión frente a actitudes que se reflejan en su vida familiar y que a ella no le interesa repetir.

«Yo no pienso hacerles nunca tarta de fresa a mis hijos», pensaba Sara para sus adentros. Porque había llegado a aborrecer aquel sabor de todos los domingos, cumpleaños y fiestas de guardar. Pero no se atrevía a decírselo a su madre, como tampoco se atrevía a confesarle que no le hacía ninguna ilusión tener hijos para adornarlos con sonajeros, chupetes, baberos y lacitos, que lo que ella quería de mayor era ser actriz y pasarse todo el día tomando ostras con champán y comprándose abrigos con el cuello de armiño. (MARTín GAITE, 1993:18)

Al lector conoce la estructura del cuento y sus relaciones jerárquicas encuentran sentido en la nueva estuctura presentada por Martín Gaite. Sara no quisiera ser ninguna Caperucita Roja, ni le gustan tampoco los cuentos de hadas tradicionales; Sara tiene una inclinación por lo que se sale de este mundo ya estructurado y quiere lanzarse a otro que percibe en otros espejos que no son exactamente los que tiene en su familia.

Sara, antes de saber leer bien, a aquellos cuentos les añadía cosas y les inventaba finales diferentes. La viñeta que más le gustaba era la que representaba el encuentro de Caperucita Roja con el lobo en un claro del bosque; cogía toda una página y no podía dejarla de mirar. En aquel dibujo, el lobo tenía una cara tan buena, tan de estar pidiendo cariño, que Caperucita, claro, le contestaba fiándose de él, con una sonrisa encantadora. (MARTín GAITE, 1993:18)

En sus lecturas del cuento, Sara no encuentra la situación amenazante como se supone que debería, no tiene miedo: el lobo le parece simpático y por tal razón no está de acuerdo con el desenlace. En la cita referida, se observa que la intención de Sara como la Caperucita de Manhattan es cambiar el final del relato tradicional, asunto que no podría conseguir si ella como lectora no tuviera otros valores que cambian la apreciación sobre el cuento y a su vez con la manera en que ella quiere vivir su vida. Para lograr este objetivo en la novela, la autora elabora una tensión entre la madre y la niña. La madre es descrita como la de la versión de Grimm, es decir, una madre de corte tradicional que se preocupa por el bienestar de su madre e hija, Martin Gaite lo acentúa: vive una vida normal, sin mirar la posibilidad de un cambio, vive de la repetición, de la seguridad, de mantener la apariencia, características resaltadas por el narrador en cada escena en la que aparece la madre, como hornear la misma tarta cada sábado, ir siempre por el mismo camino, sin desviarse, sin mirar a los lados, acompañar a su marido a un funeral, no por solidaridad sino porque es el deber ser, etc. Estas características se desarrollan en la novela (estamos ante un texto extenso, mientras que la version popular es de pocas páginas) y se presentan de modo que Sara-Caperucita no las ve como un ejemplo a seguir. De hecho, Sara no siente una conexión con su madre y lo logra con su abuela, que es un personaje que se sale de lo tradicional y que se acerca a lo que SaraCaperucita desea para su vida. A lo largo del libro pueden encontrarse múltiples 
ejemplos en torno a esta relación, y frecuentemente se usan elementos prototípicos de Caperucita para constrastar la situación.

En Caperucita en Manhattan la niña no es enviada sola al bosque a llevar comida a su abuela, como se trata de una ciudad tan grande, la niña viaja en metro acompañada de su madre, en un viaje semanal que no es emocionante para la niña y que se fastidia ante las continuas interrupciones de la madre. Su gran ilusión es poder salir al bosque-Manhattan sin la compañía de su mamá. Como segundo elemento, a Sara le fastidia la caperuza-abrigo que le obliga a ponerse su madre. Al contrario que en la versión de Perrault y de Grimm, o de incluso de la versión del siglo XI, en la que la prenda es del gusto de la niña. «Habiále dado la abuela in gorrito encarnado y le sentaba tan bien que todo el mundo la conocía con el nombre de Caperucita Encarnada» (PERRAULT, 1892:17). Sara odia el tener que llevar este impermeable encima. Por último, a Sara le da lo mismo tener que llevar tarta a la abuela porque esta ni está enferma ni le apetece la comida que su hija insite en llevarle cada fin de semana.

Le ponía un impermeable rojo de hule, lloviera o no, y le daba la cesta tapada con una servilleta de cuadros blancos y rojos. Debajo de aquella servilleta iba la tarta.

-Anda, hija, llévasela tú. A la abuela le hace más ilusión que se la lleves tú.

-A la abuela le da igual. No se fija.

-No me repliques. (MARTín GAITE, 1993: 48)

El lobo de Caperucita en Manhattan es un hombre, Mister Woolf, dueño de una afamada pastelería en Manhattan, el hombre está pasando por una crisis en su negocio y encontrar un pastel de fresas -tal y como el que prepara la madre de Caperucita- lo lleva desesperado al bosque (Central Park) y se encuentra por casualidad a Caperucita, andando por el lugar con una cesta en la que lleva la tarta de fresas semanal a la abuela. Mister Woolf, como lobo, tiene mucho del de los hermanos Grimm: motivado a actuar por hambre y glotonería, no por maldad, necesariamente. Además, como se apuntó anteriormente, para la niña protagonista las ilustraciones del encuentro del lobo con Caperucita no inspiraban miedo, sino, al contrario, deseo de conocer al personaje, de confiar en él, tal y como Sara lo decide en estas páginas.

Es este el punto central y principal de la novela: la reconstrucción a la inversa del conflicto central en Caperucita Roja, es decir, el no obedecer y desviarse del camino es lo que lleva a una aventura diferente, no hay aquí un encuentro con un lobo asesino, sino un encuentro decisivo para cambiar el destino de la abuela que, gracias a Mister Woolf, disfruta de una noche de baile como la que buscaba hacia mucho (la abuela seducida equivalente a la abuela devorada por el lobo) y la niña que, al contemplar la escena, decide volver al bosque para seguir sus propias búsquedas - de la libertad- . No quiero extenderme con el argumento de la novela, pero a medida que se llega al motivo principal del cuento y la novela, es decir, desviarse del camino, hay más paralelismos con el cuento infantil que se solucionan de modo diferente al de las versiones de hadas. El lobo que envía a Caperucita por el camino más largo, pero en cuyo trayecto ella se queda dormida, o que el encuentro 
de Mister Woolf y la abuela sea un momento de felicidad para ambos y que, ante la escena, Caperucita decida no interrumpir sino ella misma salir a buscar su propia aventura va alejándose del eje de la Caperucita Roja tradicional, distanciándose del final que ya todo el mundo conoce. Es por ello que debe concentrarse en esos elementos esenciales que le subrayan al lector de qué cuento se está hablando y de cómo Sara-Caperucita, conoce los cuentos infantiles y no le gustan, por lo que quiere cambiar los finales. Es decir, para entender mejor al relato y al personaje central se debe hacer una doble metonimia: en el relato tradicional, pasar de su estructura y eje a una reconstrucción y apertura que se aprecia mejor si se equiparan las dos versiones $\mathrm{y}$, en cuanto al personaje, entendido como la posibilidad de extender sentidos cuando se conoce la literatura y se proponen lecturas diferentes, que mezclan fuentes y épocas y se salen de los desenlaces típicos. Caperucita transgrede y desobedece, pero al hacerlo encuentra lo que quiere, esto es, entre otras cosas, tener su propio yo alejado de lo que ve en su madre, que es la representación de una mujer conservadora y tradicional. Sin tener una intención moralizante, la novela se enfoca en mostrar de qué manera la literatura contribuye a armar el libre albedrío y el pensamiento, distanciándose de la lectura tradicional de la desobediencia como condena e indagando más bien en la transgresión como posibilidad de conocimiento, asunto que resalta FERNÁNDEZ LAMARQUE (2014) en su aproximación filosófica a este libro, al mencionar «la preocupación del texto por articular la naturaleza de una vida ética y secular en la modernidad» (7).

\subsection{Una caperucita doblemente imaginada: la versión de Pescetti.}

Por último, nos referiremos a Caperucita Roja, tal y como se la contaron a Jorge (1996), del argentino Luis Pescetti. Esta versión está clasificada como literatura infantil y álbum ilustrado. Se trata de una versión cercana a la versión de Grimm pero con una particularidad: como dice el título, es una segunda versión a partir de una versión ya contada. Es decir que desde el título se plantea la relación intertextual. Como se trata de una versión gráfica el relato, se cuenta a través de dos viñetas que se yuxtaponen página a página. En una, la versión tradicional contada en colores sepia (para acentuar que se trata de esta versión), y en la otra, una variante contada por un padre de familia a Jorge, su hijo (esta sí ilustrada a todo color). La versión en sepia recoge todos los motivos ya mencionados más atrás: la acción situada en el no tiempo de los cuentos de hadas, los personajes ataviados con vestidos del siglo XIX y el escenario un paisaje típico alemán, usual en las ilustraciones de los cuentos de los hermanos Grimm (aspecto importante en esta versión por tratarse de una narración con gran peso de lo gráfico), las secuencias más conocidas -y que ya se han enumerado aquí- están relatadas en cada viñeta.

En contraste con este relato está el que el lector comprende y asimila a partir de lo narrado. Se trata del niño que por primera vez está escuchando este cuento. Para empezar, el nombre mismo, Caperucita, causa extrañeza en el niño que no alcanza a imaginarse qué es una caperucita roja, ya que, exceptuando el cuento infantil, es poco usual el uso de este vocablo en la vida cotidiana, por tanto el niño se imagina que caperuza roja significa, quizá, una niña con la cara roja, y así sucede con los demás elementos que va describiendo el narrador: la comida que le lleva la niña a la abuela es una pizza, porque seguramente un niño de finales del siglo XX no se 
imaginaría llevando un cesto con tarta de manzanas, miel o vino a la abuela. El lobo retratado es cercano al de los dibujos animados, como una caricatura, alejado del lobo feroz de las ilustraciones clásicas. En esta descripción connotativa-denotativa hay dos aspectos que sobresalen: el primero, cuando el padre le cuenta del bosque, se nos pinta un bosque color sepia con una cabaña tradicional alemana, un bosque de árboles tupidos y altos y una liebre de fondo; podríamos decir que es una imagen muy usual para representar el paisaje de tales cuentos, mientras que el niño se imagina un bosque muy diferente, más cercano tal vez a su idea de bosque: palmeras, árboles tropicales, serpientes y monos, subrayando que el bosque de los cuentos de hadas es muy diferente de los bosques que un niño lector pudiera encontrar en América Latina o, como segunda posibilidad, al imaginarse la palabra bosque se remite a un lugar exótico que no visita mucho, como si fuese una selva. La otra ilustración importante tiene que ver con la forma en que el niño se imagina a los personajes adultos. En la primera escena ilustrada del libro se nos representa a la mamá y al papá del niño. Cuando el niño se imagina a la mamá de Caperucita tiene el rostro de su mamá y cuando se imagina al cazador rescatando a Caperucita se imagina a un superhéroe con vestimenta tipo Supermán y con el rostro de su padre. Estos dos ejemplos resaltan cómo el niño construye significado a partir de referentes conocidos y cómo la figura materna y paterna se constituyen fundamentos de la vida infantil.

Caperucita Roja tal y como se la contaron a Jorge reconstruye lo que se ha estado describiendo en estas líneas, presenta la versión clásica contrastada con la adaptación moderna. Coteja los dos planos que se entrecruzan y elaboran significados nuevos, siempre a partir de un texto base -Grimm, Perrault- y esta reconstrucción se arma a partir de elementos que se corresponden con la ideología del autor y con los saberes previos del lector. Esta última adaptación apela pues a la lectura de un cuento que en este caso se dirige no solo al niño, en un doble juego porque cualquier lector tiene una lectura de este cuento pero también hay otro niño -Jorge- que está escuchado el mismo cuento por primera vez; hay cabida, a su vez para un tercer lector, el mediador de lectura, en este caso el padre, que está leyendo el cuento a Jorge y que aparece siempre en el plano izquierdo del texto, en color sepia, marcando diferencia con el lector infantil-Jorge de la derecha, que está armando el sentido del texto y que emplaza como un héroe a su padre.

Cada lector encierra un saber diferente y una aproximación al texto particular. Para el padre de Jorge se trata de un cuento clásico con unas estructuras que siguen siendo las mismas de hace varios siglos o las propias de una imaginación cautiva por los estereotipos actuales acerca de este cuento. Para Jorge es un cuento nuevo que va armando desde lo que le es familiar y conocido. Y habría un tercer lector, fuera del plano narrativo que identifica a los dos primeros lectores y consolida dicha relación intertextual. Pero esta interpretación del texto no sería la única, pues no puede dejarse de lado la intencionalidad del autor al poner de modo explícito al papá como el héroe del cuento en la versión de Jorge. Es el mismo padre que toma parte de su tiempo para estar con su hijo y para -como lo hace en la parte final del álbumcocinarle y pasar tiempo juntos. Si bien el padre no es un cazador que lo salve de las fauces del peligro, si es un héroe para su hijo a través de esos sencillos actos cotidianos que van construyendo y enriqueciendo la relación que llevan. 
La moraleja de este álbum ilustrado se aparta de la versión clásica, el relato de la niña que se desvía del camino es solo una anécdota que muestra como fondo el peso de los relatos tradicionales en la vida familiar para crear lazos entre padres e hijos, de nuevo hay una resignificación del cuento alejándose de los valores que tradicionalmente se le han atribuido, es decir, aquí no hay intención de destacar o condenar la desobediencia o la maldad. Es un relato que se vale de la anécdota popular para contar un relato nuevo que toma las estructuras del cuento y crea uno inédito, con nuevos sentidos que se articulan desde la base del cuento tradicional, pero que se desvían del mensaje o moraleja del que está investido.

\section{Conclusión}

Los cuentos de hadas encarnan lo humano y cada lector encuentra equivalencias explícitas o implícitas consigo mismo, arquetipos que trascienden al texto escrito y que delatan la importancia que siguen teniendo estos textos en el imaginario cultural. Además, estos tipos de relatos parecen tener una función social gracias a la cual son reeditados, reelaborados o revisados y de esa forma confluyen en una suerte de circuito que los mantiene vigentes y los adecúa a distintos sistemas de valores en distintas sociedades y momentos históricos.

Los cuentos tradicionales siguen haciendo parte del saber lector tanto de niños como adultos. Su lugar dentro de los procesos lectores de los niños sigue siendo fundamental y los nuevos abordajes son permanentes, tanto en el mundo de la literatura como en el mundo audiovisual. A través de los tres ejemplos presentados puede verse que desde estas relaciones intertextuales los escritores no solo están reconstruyendo la versión tradicional de un cuento de hadas, sino mostrando de qué manera un lector, a partir de sus saberes previos construye el sentido de un texto, desde su propio contexto, como lo vemos claramente en Caperucita Roja tal y como se la contaron a Jorge hasta la transgresión y parodia que surge luego de entretejer esos saberes para elaborar nuevos sentidos a través de la literatura. Caperucita Roja $y$ otras historias perversas y Caperucita en Manhattan, muestran esas infinitas posibilidades de reescritura, adaptación e interpretación en estos cuentos que parecen interpelarnos sobre las cosas que todavía no conocemos o reconocemos.

\section{BIBLIOGRAFÍA}

ARCINIEGAS Triunfo (2003), Caperucita Roja y otras historias perversas, Bogotá, Panamericana.

MARTÍN GAUTE Carmen (1990), Caperucita en Manhattan, Madrid, Siruela.

FERNÁNDEZ LAMARQUE María (2014), Una lectura filosófica de Caperucita en Manhattan en CLIJ: Cuadernos de literatura infantil y juvenil, Año $\mathrm{N}^{\circ} 27, \mathrm{~N}^{\mathrm{o}}$ 258,2014 , p. 6-15.

GRIMM Jakob Ludwig (2013), Cuentos de los hermanos Grimm. San José, Imprenta Nacional

GonZÁlez Susana, (2003), ¿Existía Caperucita Roja antes de Perrault? Cuadernos de literatura infantil y juvenil, Año $\mathrm{N}^{\circ} .19, \mathrm{~N}^{\circ} .158, \mathrm{p} .16-22$. 
MANGIONE CÁRDENAS Noelia (2018), Para leerte mejor: nuevas miradas sobre la figura del "Lobo feroz" en Boletín GEC: Teorías Literarias y prácticas críticas, No. 22, p. 101-116.

PERRAUlT Charles (1892), Cuentos de Perrault, Madrid, Biblioteca Universal.

PESCETTI Luis (1996), Caperucita Roja, tal y como se la contaron a Jorge, Alfaguara, Buenos Aires.

NogUeROL JimÉNEZ Francisca (2001), La metamorfosis de Caperucita, in: Mattalía Sonia, GiRONA FiBla Nuria (coord.), Aun y más allá: mujeres y discursos, Caracas, Escultura, p.113-122 